\title{
Study on the Impact of Road Cycling on Event Tourism Development in Guilin of China
}

\author{
Liang Feng ${ }^{1}$, Lin Zengxue ${ }^{1 *}$ \\ Guilin Tourism University, Guilin, China \\ lf@gltu.edu.cn
}

\begin{abstract}
Guilin is a famous tourism city in China. Guangxi has held multiple international road cycling events. The distribution of events connects Guilin and the surrounding counties and cities. The holding of events has both positive and negative effects on the development of Guilin's tourism resources. This paper analyzes the positive and negative effects of the development of event tourism, and puts forward strategies on how to develop event tourism in Guilin by using road cycling events.
\end{abstract}

Keywords—Road cycling; Sports tourism development; Guilin of China

\section{INTRODUCTION}

Road cycling, rising in 1790 , is a comprehensive sport challenging speed and endurance. The scenery along the race track is natural and beautiful, which also brings warmth and comfort to this unusually hard sport. In 1869, the earliest road cycling event was held in France. The race track was 120 kilometers from Paris to Lyon. Later, the cycling event develops continuously and becomes the world's most famous Tour of France.

Guilin has developed tourism and rich tourism resources for leisure sightseeing cycling and adventure fitness cycling, which provides a favorable guarantee for the development of bicycle tourism in Guilin [1]. At the same time, focusing on China's "The Belt and Road" cultural exchange and combining with its own characteristics, Guilin extensively carries out cycling events. The competitive events and cycling tour activities strengthen the body, deepen the understanding, build friendship, convey different cultures, and play a positive role in promoting the development of event tourism.

\section{TOUR OF GUANGXI CYCLING EVENT}

Tour of Guangxi road cycling, equal to the world's top event, is the only world tour event of road cycling in Asia. It will be held in Guangxi in October every year for five consecutive sessions as approved by the organization. The race track starts from Beihai, via Nanning-Liuzhou and ends at Guilin. In the promotion of the event, the competition attracted CCTV sports channel, Tourism TV, Guangxi TV, Tencent Sport and other domestic broadcasting platforms for whole or part video live broadcast. The events were reported in Guangxi by hundreds of media and nearly 400 media professionals in the world.
The holding of the event has not only promoted the popularity of Guilin, but also increased economic income during the event and attracted many investors. At the same time, it also has a profound impact on the development of sports industry and the development of event tourism resources in Guilin.

\section{IMPACTS OF CYCLING EVENTS ON TOURISM DEVELOPMENT IN} GUILIN

\section{A. Positive impacts of the event on tourism development in Guilin}

1) Enhancing the image and popularity of Guilin as a tourism city

Road cycling is an important content of sports tourism in recent years. At the same time, it attracts the attention of people of many age groups in society. With the holding and propaganda of events, more and more people begin to pay attention to Guilin, begin to understand the tourism city image of Guilin, and more people begin to pay attention to Guilin's cultural and historical culture. In particular, the attention of foreign friends to Guilin is increasing year by year. That is to say, many people begin to notice the city of Guilin because of the road cycling events, and visitors watching the games at the scene will go sightseeing in various tourist attractions. They begin to pay more attention to the culture and history of Guilin, and also have a more comprehensive understanding of the city of Guilin.

\section{2) Improving tourism infrastructure}

In order to attract more tourists and better display the tourism resources of Guilin, in recent years, Guilin government has greatly improved the tourism infrastructure, including the construction of urban tourism and the service system of scenic spots, in accordance with the geographical advantages of Guilin and the demand for tourism consumption. It is mainly to construct a large tourism traffic pattern, and to build a modern tourism comprehensive transportation system with aviation, high-speed railway, intercity railway and expressway as the main framework, tourist center cities and port cities as a fulcrum, and trunk road, special road of scenic spots and inland river shipping as complement, so as to realize the interconnection, intercommunication and convenient connection of air, land and water transportation. Speed up the construction of Nanning, Guilin Liangjiang International Airport and feeder airports of major tourist attractions, 
introduce supporting policies for the construction of tourist roads, increase the input to the construction of tourist roads to the scenic spots, expand the scale of tourist accommodation, increase the number of star rated hotels, and focus on the development of featured theme hotels of holiday type, conference type, health maintenance type and culture type, vigorously develop home inns, youth hostels, RV camp and other special accommodation, to form a tourist accommodation service system with complete facilities, good service, reasonable layout and coordinated grades; establish catering service gathering areas and cultivate brand flavor catering. Introduce international catering brands and encourage catering enterprises to chain and collectivize. Establish a normalized and standardized management system for tourist catering. Carry out comprehensive tourism information construction, further improve the information level of tourism management, service and marketing system, improve the technical support and standardization level of tourism informatization, and establish and improve the operation and guarantee system of tourism informatization.

\section{3) Increasing the number of tourists and consumption}

Cycling is a sport that is popular with the public and can be experienced, without the need to distinguish age and gender. Everyone can participate in, and everyone can easily understand the schedule and the events and compare the contents, so it is easier to be accepted and watched by the public. Road cycling events usually include pre-competition notifications, preliminaries, finals and other itineraries. Depending on the size of the game and the duration of the game, the consumption of the visitors attracted will vary. In recent years, the tourism consumption of Guilin has increased year by year, which is inseparable from the development of road cycling events.

Since 2009, the Red Bull cup cycling invitational held in Nanning and Beihai, has developed from the exploratory nature in the initial stage into an influential amateur cycling event in China at the end of a year and at the beginning of winter. And the domestic amateur cycling events have transformed from single item type and extensive type in the previous years to comprehensive type and carnival type. Since then, all regions in Guangxi have been keen on this healthy national event, and the road cycling schedule held by Guangxi includes Guilin every year. The holding of road cycling events increased the number of tourists to Guilin. From 3,293 in 2012 to 5,385 in 2016 , it has increased more than twice. Among them, domestic tourists increased from 3,111 in 2012 to 5,152 in 2016, which has increased by 0.6 times. Although the number of inbound overnight tourists increased less than domestic tourists, it has increased year by year [2].

TABLE I. STATISTICS OF DOMESTIC AND FOREIGN TOURISTS RECEIVED BY GUILIN

\begin{tabular}{cccc}
\hline Year & $\begin{array}{c}\text { Domestic and foreign tourists } \\
\text { received (person/time) }\end{array}$ & Domestic tourists (person/time) & $\begin{array}{c}\text { Inbound overnight tourists } \\
\text { (person/time) }\end{array}$ \\
\hline 2012 & 3293 & 3111 & 182 \\
2013 & 3584 & 3390.5 & 193.7 \\
2014 & 3871.16 & 3667.84 & 203.32 \\
2015 & 4469.95 & 4253.61 & 216.32 \\
2016 & 5385.87 & 5152.55 & 233.32 \\
\hline
\end{tabular}

a. Data source: Statistical bulletins on national economy and social development of Guilin Statistical Bureau in 2010 -2016

In 2012, the total tourism consumption of Guilin was RMB 26.68 billion, and it increased to nearly 2.3 times in 2016 year. The total domestic tourism consumption increased rapidly, and the international tourism consumption increased steadily year by year [2].

TABLE II. STATISTICS OF TOURIST CONSUMPTION OF GUILIN

\begin{tabular}{cccc}
\hline Year & $\begin{array}{c}\text { Total tourism consumption } \\
\text { (hundred million yuan) }\end{array}$ & $\begin{array}{c}\text { Total domestic tourism } \\
\text { consumption } \\
\text { (hundred million yuan) }\end{array}$ & $\begin{array}{c}\text { International tourism } \\
\text { consumption } \\
\text { (hundred million yuan) }\end{array}$ \\
\hline 2012 & 276.87 & 230.48 & 46.39 \\
2013 & 348.48 & 294.63 & 53.85 \\
2014 & 420.3 & 360.77 & 59.53 \\
2015 & 517.33 & 453.51 & 63.82 \\
2016 & 637.31 & 558.81 & 78.5
\end{tabular}

\footnotetext{
b. Data source: Statistical bulletins on national economy and social development of Guilin Statistical Bureau in 2010 -2016
} 


\section{4) Driving tourism employment opportunities}

To hold sports event in a city, the whole process of planning - formulation - implementation - completion will usually last for half a year, or even more time. The work needs a lot of labor to carry out the details. With the scale expansion of road cycling events, the demand for staff will be increased. The holding of events can promote local tourism employment opportunities, thereby stabilizing social order and increasing the tourism employment structure.

\section{B. Negative impacts of events on tourism development of Guilin}

\section{1) Crowding-out effect}

In economics, crowding-out effect means that, in a relatively balanced market, as the supply and demand increase, some funds are squeezed out from the original advance and flow into new goods. The crowding-out effect in this paper means that, before and during the road cycling events, some people will worry about the short-term increase of consumption in Guilin, or the people who do not like cycling and intend to come to Guilin will give up the plan to travel in Guilin based on this. In such case, to some extent, the crowding-out effect of the holding of road cycling events affects the tourism consumption of Guilin.

\section{2) Traffic congestion}

Road cycling is different from regular sports events. Common sports events mostly use indoor venues; even outdoor venues are relatively concentrated. The venues of road cycling are usually surrounding the main trunk roads of the city. And it needs long time and wide range. Many tourists come to watch the event and gather on the main trunk roads. This will cause traffic congestion one or two days before the event and during the event. To ensure the smoothness of the game event and the safety of tourists, some roads are even closed to traffic, and some sections prohibit pedestrians from passing, which brings inconvenience to the lives of the residents.

\section{3) Rising prices}

The theory of market supply and demand suggests that when the demand of the market increases, the price will increase. In the same way, during the road cycling schedule, the influx of tourists to the city will result in the increase of catering, living and other consumption prices in the city. Although under the action of the market mechanism, such a situation is inevitable, some unlawful vendors seek for their own interests, which will bring negative impact on the city.

\section{4) Environmental pollution}

While watching road cycling, many tourists to Guilin will visit other scenic spots and will stay for a few days in Guilin. The overload in the scenic spots will increase the endurance of scenic spot management and bring new difficulties to the management of scenic spots. For example, some tourists throw rubbish and scribble on important buildings. At the same time, during the rush hour, as a means of transport, the emission of vehicles will increase, resulting in serious environmental pollution to the city.

\section{COUNTERMEASURES FOR THE DEVELOPMENT OF CYCLING EVENT TOURISM RESOURCES OF GUILIN}

\section{A. Creating brand effect}

Guilin road cycling event was originally held by clubs, now it is hosted by the government, and it has already had a large scale. From the analysis on the positive impact of road cycling events on the development of Guilin's tourism resources in recent years, it can be seen that road cycling is a sporting event that can attract different levels of tourists for sightseeing. At present, all cycling events held by Guilin government are large provincial tour games sponsored by Guangxi and co-organized by Guilin government. The road cycling games held in Guilin is mainly club games sponsored by the society, and the number of times every year is relatively small. In order to make road cycling a local tourism brand, it is suggested that the local government should develop more policies, expand the scale of cycling and increase the number of times to attract more business opportunities from tourism, to form the state of increasing tourism consumption during the event and maintaining economic benefits created by the brand after the event, and make road cycling events as popular as the landscape of Guilin, as the city's landmark tourism brand.

\section{B. Innovating service management}

Taking the road cycling events as the breakthrough point, in the process of developing Guilin's sports tourism resources, innovate service management, increase local sports tourism products, control the floating rise of consumer prices, stabilize the social order and promote the development of local economy.

\section{1) Increasing financial support}

Any social activities need funds; similarly, the holding of road cycling will also need a lot of financial and material resources. To increase support for cycling events, first of all, invest a lot of financial resources to ensure adequate funding for the event. The funds needed for the event can be allocated from the early budget of the government, and the better way is to introduce social forces. Generally, the government can encourage donation of caring people in the society and title sponsorship of enterprises. This method not only alleviates the government's financial pressure, guarantees the fund demand of the events, but also carries out brand promotion for enterprises that participate in the form of title sponsorship.

\section{2) Strengthening environmental protection work}

Before the event, conduct environmental assessment of the overall schedule, give environmental guidance for scenic spots, and increase propaganda via civilized viewing banners. Remind tourists to maintain environmental hygiene, and to alleviate traffic congestion in the city, the government supplies tourist buses during the events, which are moored in the form of city grid. Guide tourists to visit scenic spots and watch games with tourist buses, minimize the use of self-used vehicles, and reduce the loss caused by crowding-out effect. 


\section{3) Standardizing tourism market}

During the events, the reception tasks of various scenic spots are heavy and hotels and restaurants are also overload. Therefore, the government has issued policies, which allow the overloaded entities to increase the price of services and goods in a certain degree, but not to overcharge aimlessly. Comb the market system, and post price catalogs in the major scenic spots and hotels tourists live in at the same time, to prevent tourists from being deceived and the negative impact to the city.

\section{Event propaganda}

The development of tourism resources not only needs the geographical advantage and the charm of Guilin itself, but also needs more people to know the sport of road cycling events. Carry out propaganda by binding the official micro-blog and the scenic spots of Guilin, to make more people know Guilin and understand the road cycling events. At the same time, cooperate with the famous tourism cities in China to promote the events and attract more tourism resources and business opportunities.

\section{CONCLUSiON}

Guilin is a famous tourism city in China. For thousands of years, the beautiful scenery and pleasant climate are the unique charm of Guilin. With the competition of tourism economy, as a city tourism image, road cycling event is an important link in promoting the development of Guilin's tourism resources. A Road cycling event have positive significance on Guilin's tourism resources, but also has a certain negative impact. Encourage the sustainable development of the positive effect and reduce the negative impact. And encourage the development of tourism resources by creating city brand, innovating service management and event propaganda.

\section{ACKNOWLEDGMENT}

This paper is one of the Guilin Tourism University Scientific research fund Project (2016ZD06). Also is one of the phased achievements for the research subject: Research on Integrative Development of Guangxi leisure Sports Industry and Tourism Industry (17FTY004). And one of research results funded by Guilin Tourism University key discipline tourism management Research funding project.

Author: Liang Feng (1983- ), male, born in Zibo in Shandong Province, doctor of sports, lecturer, and research area: leisure sports tourism industry.

Communication Author: Lin Zengxue (1965- ), male, born in Cangzhou in Hebei Province, Master's degree, Associate professor, and research area: Tourism management.

\section{REFERENCES}

[1] F. Liang. Research on the Characteristics of Leisure Cycling Tourism and Development Strategies[A]. International Conference on Education Science and Economic Management(ESEM 2017)[C]. 2017:10.

[2] Guilin Municipal Bureau of Statistics.[EB/OL]. http://www.gltj.gov.cn

[3] L. Chen, Y. Hu. The Influence of Mountain bike race on Tourism resources development in Guizhou [J]. Contemporary Sports Technology, 2016, 6(34):220-220.

[4] Z. W. Qin. A study on the Prospect of Guilin City's Bicycle Tourism Market [D]. Thesis for master Degree in Guangxi Normal University, 2014. 